www.mdpi.com/journal/remotesensing

Article

\title{
The Stalled Recovery of the Iraqi Marshes
}

\section{Richard H. Becker}

Department of Environmental Sciences, University of Toledo, $2801 \mathrm{~W}$ Bancroft Ave, Toledo, OH 43606, USA; E-Mail: richard.becker@utoledo.edu; Tel.: +1-419-530-4571; Fax: +1-419-530-4421

Received: 5 December 2013; in revised form: 22 January 2014 / Accepted: 26 January 2014 / Published: 30 January 2014

\begin{abstract}
The Iraqi (Mesopotamian) Marshes, an extensive wetlands system in Iraq, has been heavily impacted by both human and climate forces over the past decades. In the period leading up to the Second Gulf War in 2002, the marshlands were shrinking due to both a policy of draining and water diversion in Iraq and construction of dams upstream on the Tigris and Euphrates rivers. Following the war through 2006, this trend was reversed as the diversions were removed and active draining stopped. A combination of MODIS and GRACE datasets were used to determine the change in surface water area (SWA) in the marshes, marshland extent and change in mass both upriver in the Tigris and Euphrates watersheds and in the marshlands. Results suggest that the post war dam removal and decreased pumping in 2003 provided only temporary respite for the marshlands (2003-2006 SWA: 1,477 km² increase (600\%), water equivalent depth (WED): $+2.0 \mathrm{~cm} / \mathrm{yr}$.; 2006-2009: $-860 \mathrm{~km}^{2}$ (-41\%) WED: $-3.9 \mathrm{~cm} / \mathrm{yr}$.). Unlike in the period 2003-2006, from 2006 forward the mass variations in the marshes are highly correlated with those in the upper and middle watershed $(\mathrm{R}=0.86$ and 0.92 respectively), suggesting that any recovery due to that removal is complete, and that all future changes are tied more strongly to any climate changes that will affect recharge in the upper Tigris-Euphrates system. Precipitation changes in the watershed show a reduction of an average of $15 \%$ below the $15 \mathrm{yr}$ mean in 2007-2011 This corresponds with published ensemble predictions for the 2071-2099 time period, that suggested similar marshland shrinkage should be expected in that time period.
\end{abstract}

Keywords: Iraqi marshes, GRACE; MODIS; Tigris; Euphrates; climate 


\section{Background/Rationale:}

The Tigris-Euphrates (T-E) river system has been influenced by the interplay between natural systems and human alteration for at least the past 7,500 yr [1], and this still continues today. The region, also known as the Fertile Crescent, is home to early agricultural activities due to historically plentiful water and seasonal flooding. This seasonality and variability in snowmelt and upstream rainfall, combined with increased upstream water demands has caused intense modification of the entire system. Discharge from this system through the Shatt el Arab provides most of the freshwater into the Arabian/Persian Gulf (referred to hereafter as the Gulf).

The T-E watershed extends approximately $880 \times 10^{3} \mathrm{~km}^{2}$ over the countries of Turkey, Iraq, Syria, Iran and Kuwait [2]. Prior to significant alterations, the combined flow of these rivers emptied out through distributary channels into the Iraqi Marshes before entering the Gulf through the Shatt el Arab. Both rivers derive significant water from snowmelt from the northern mountains high in the basin (Figure 1). Based on the 1998-2013 record of Tropical Rainfall Measurement Mission (TRMM), total precipitation averaged across the entire recharge area is approximately $330 \mathrm{~mm} / \mathrm{yr}$. Most of the precipitation falls in the upper elevations in the northern region of the watershed, and flows south through Turkey and Syria, before entering Iraq. Historical discharge of the combined rivers before the early 1970s amounted $\sim 80 \times 10^{9} \mathrm{~m}^{3} / \mathrm{yr}$. [3], but this has been reduced by more than $50 \%$ by upstream water withdrawals [4]. The highlands of Turkey provide $88 \%-98 \%$ of the water that flows in the Euphrates, though minor contributions come from the Syrian highlands with only very small amounts originating from within the Iraqi borders [5]. The Tigris River receives only $32 \%-50 \%$ of its flow from these highlands, whereas the remaining flow comes from numerous tributaries that derive their water from the Zagros Mountains that straddle the Iraq-Iran border [5].

The marshes cover between 12 and $20 \times 10^{3} \mathrm{~km}^{2}$, and are currently fed by channelized distributary channels from the Tigris and Euphrates rivers. The marshes are divided into three main units: the Hammar Marshes, the Central or Qurnah Marshes, and the Hawizeh Marshes [3,4]. Elevation differences across the plains are very low, as little as $4-8 \mathrm{~cm} / \mathrm{km}$ over the central portion of the marshes [4]. These overlie clay rich soils. This combination means that this area responds rapidly to changes in water inputs.

Over the past several decades, there have been substantial alterations in the flow of water into the marshes. These fall under two categories: (1) upstream dam construction (e.g., Turkey's Greater Anatolian Project (GAP)); and (2) in marsh water diversions such as dams, canals pumping stations barrages and diversions. The purpose of the upstream dams is twofold. These have been introduced to provide hydropower and reservoirs for irrigation and drinking water. For example, in Syria alone, the total irrigated land area doubled between 1985 and 2002, where the rapid expansion of agricultural land is attributed primarily to government policies supporting the objective of food self-sufficiency [6]. In Turkey, over 20 dams on the Tigris and Euphrates rivers have been constructed as part of GAP [3,7]. These projects are anticipated to provide irrigation for an area in excess of 1.8 million ha $[8,9]$.

The dams, canals and diversions in the marshes themselves have served several purposes. Initially, they were constructed to control water from the distributary channels, either through canals to redistribute water, or dams and diversions to limit seasonal flooding. In the 1990s, modification was intensified, as water was channelized through the marshes, and wet portions pumped out. For political 
and military reasons, by 2000 , these marshes had been effectively pumped out, with less than $10 \%$ of their original extent remaining [4].

Figure 1. Extent of the Tigris-Euphrates watershed overlain on MODIS NDVI image showing areas of high vegetation (green). Red Boxes show area of upper watershed $(5 \times 5$ degree box $)$, middle watershed $(3 \times 3$ degree box $)$ and marshes $(1 \times 1$ and $3 \times 3$ degree box), shown from NW to SE, used in GRACE analysis. Inset shows Tropical Rainfall Measurement Mission (TRMM) precipitation over the watershed is concentrated in the North, through Eastern Turkey, Northern Iraq and Western Iran.

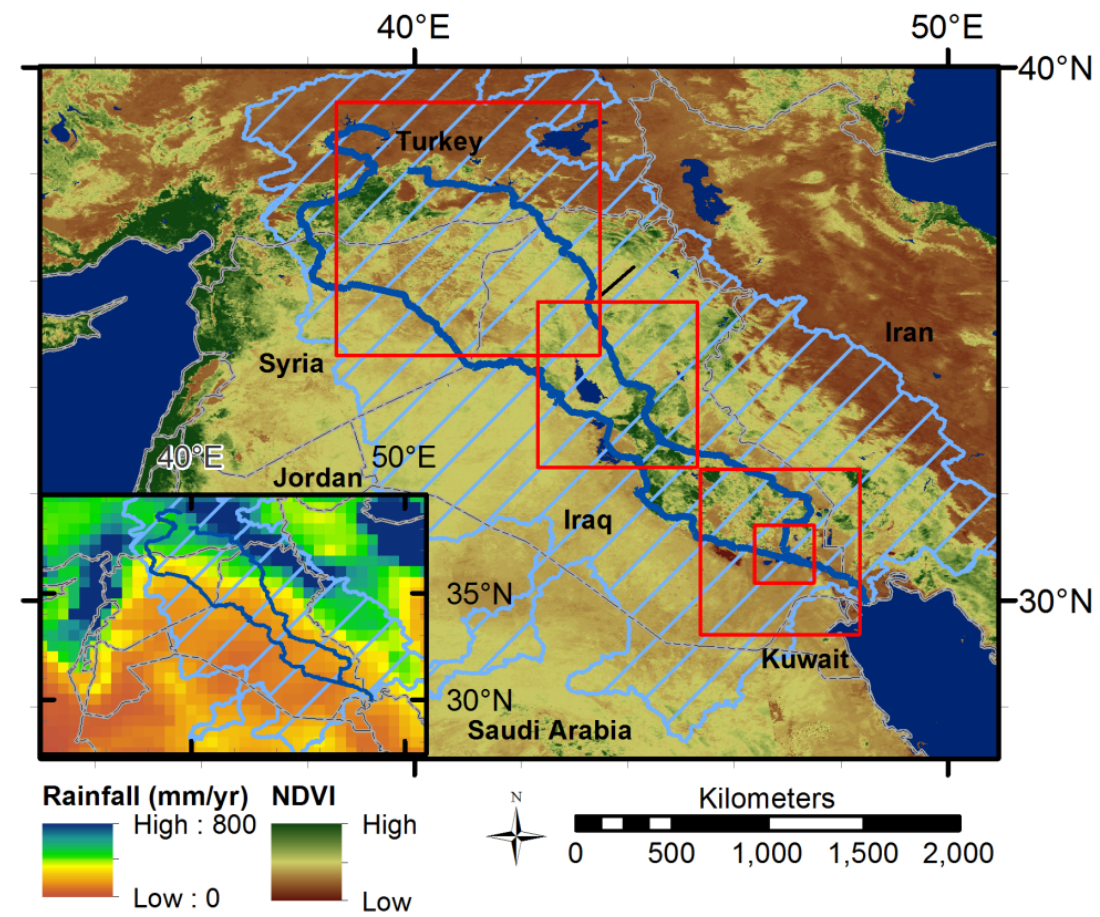

The combination of approximately 60 engineering projects that eliminated seasonal flooding and reduced natural flow precipitated the dramatic reduction in areal extent of the marshes, from $8,000 \mathrm{~km}^{2}$ in 1966 to $750 \mathrm{~km}^{2}$ in 2002 [3]. During and following the Second Gulf war in 2003, many dams were destroyed and pumps disabled, allowing the marshes to begin to recover. Based on past records of flow and marshland extent, Jones et al. [3] made predictions about recovery extent if the marches were allowed to establish equilibrium with the Tigris-Euphrates system, as had previously been the case.

Following the Second Gulf War, access to this field area has become problematic due to ongoing military and insurgent activities. Records previously well kept on river flow (e.g., those used in Jones et al. [3]) are not kept up to date, or are effectively impossible to obtain. As a result, remote sensing techniques provide a way to investigate this system that would otherwise not be possible. A combination of remote sensing techniques which look at both changes in areal extent and water mass variations, make it possible to examine changes in this system which would otherwise be data poor.

The Iraqi Marshes are considered a valuable cultural heritage site [4] and provide significant valuable habitat to local wildlife populations and migratory birds [10]. Understanding how they have recovered following the cessation of pumping and removal of dams, and how they connect to the Tigris-Euphrates river system is essential in determining future reconstruction possibilities for the marshes. 


\section{Objectives}

The overall purpose of this study is to assess aspects of the response of the Iraqi Marshes during the period of 2003-2012. This period directly follows the intensive localized human intervention that occurred during the 1990s through roughly 2002, and continues to be subject to ongoing human activities at a greater distance (dam construction and increased water retention in the upper portions of the T-E basin). This period also shows responses to changes in water available due to changes in weather and climate.

The first objective is to assess the ability of Gravity Recovery and Climate Experiment (GRACE) to resolve changes in water storage in a smaller than typically examined area: the Iraqi Marshes. I hypothesize that trends in water storage seen as combined surface water area changes and vegetation extent of the marshes that are readily observed in Moderate Resolution Imaging Spectroradiometer (MODIS) data can be identified using GRACE data, similarly to how total storage changes have been identified in the upstream areas by Voss et al. [11] and Longuevergne et al. [12].)

The second objective is to use GRACE mass variations to examine how the marshes have responded to the human disturbances of dam removal and upstream water storage. I put forward that if the system is recovering from nearby interventions, water mass in the marshes and areal extent of the marshes should increase independently of upstream storage changes. If mass and extent of marshes are controlled by upstream diversions, the mass in the marshes should go down as the upstream reservoir mass goes up. If mass trends in the upstream and downstream areas vary together with only a brief ( $<3$ month) time lag, this would indicate that marshland extent is responding to changes in precipitation and recharge in the upstream portion of the system.

\section{Approach}

Previous studies have use GRACE data to assess change in surface and groundwater storage in the upper and middle portions of the T-E basin from 2003 to 2009 [11,12]. Using a model based on a combined GRACE water mass variation data and Global Land Data Assimilation System (GLDAS) surface water budget data [13], Voss et al. [11] noted a $-147 \mathrm{~km}^{3}$ change in water equivalent mass in the upper portion of the T-E basin, and attributed most of that mass loss to groundwater removal. Longuevergne et al. [14] noted a similar mass reduction, but argues that these should be attributed to changes in mass due to large changes in water levels $(>7 \mathrm{~m})$ in a number of large surface reservoirs, which are not well simulated in the GLDAS model. In either case, they show a reduction in available water throughout the period of 2003-2009.

During the same time period and beyond, the Iraqi Marshes are seen to undergo a different pattern, starting with a period of substantial recovery, followed by a very rapid decline. In order to study what role upstream factors played in the pattern of recovery in the marshes located in the lower portion of the T-E watershed, an analysis of water mass variations was conducted throughout the T-E basin, with special attention paid to the Iraqi Marshes (Figure 1). The combination of GRACE gravity data and a VIS/IR optical (MODIS) dataset, supplemented with Tropical Rainfall Measurement Mission (TRMM) precipitation data provide a unique way to assess these differences. MODIS allows for a high quality assessment of both vegetated area and open water area to measure changes in marsh extent. 
GRACE uniquely allows the measurement of variations in water mass storage in a system. This allows for the examination of relationships between the two. Adding TRMM allows for the incorporation of precipitation over the entire watershed, from which variations in available water can be assessed.

TRMM precipitation was used to assess variations in precipitation over the entire watershed. To assess the surface extent of this change over the marshes, MODIS imagery was used to examine the trends of open water recovery throughout the 2003-2013 time period. GRACE gravity data was utilized to examine the change in total storage throughout the Iraqi Marshes and in locations throughout the T-E basin. The GRACE data was interpreted to help understand how the marshes have become re-coupled with the T-E river system. In this light, interpretations are made about the future possible effects of climate change, utilizing published forecast models to draw inferences about future marsh extents.

\section{Methods}

To assess the variations in water mass associated with the Iraqi Marshes, combined with mass changes throughout the recharge area, results from the GRACE mission, which consists of monthly satellite based gravity field measurements, were used. GRACE satellite observations of the time-variable mass associated with water movement generate a dataset which can be utilized to assess the changes in water mass distributions throughout large basins [15]. GRACE provides a record of total variations in water storage, which are a summation of the components from groundwater, surface water, soil moisture, and snow pack [16].

One hundred and sixteen (116) months of terrestrial water equivalent thickness data (from 2003 to 2013) derived from the GRACE system were analyzed, using water storage computed from the RL05 JPL dataset, post-processed and distributed through http://grace.jpl.nasa.gov as the Grace Monthly Mass Grids-Land product. In this 1 degree gridded dataset, GRACE data were processed to produce monthly water anomalies in total water storage relative to mean water storage over the entire time period [17]. The land gridded data used are based on the RL05 spherical harmonics from JPL. This solution uses the degree 2 order 0 coefficients derived from Satellite Laser Ranging by Cheng and Tapley [18] and the degree 1 coefficients are those derived by Swenson et al. [19]. From this, a postglacial rebound signal in the data has been removed according to the model of Paulson et al. [20], as revised by Geruo et al. [21]. In addition, a destriping filter is applied to the data, to minimize the effect of an error which is seen as N-S stripes in GRACE monthly maps. To this, a $200 \mathrm{~km}$ wide gaussian filter is applied to the data as well as a spherical harmonic filter cutoff at degree 60 . Further details of the processing of these datasets is described by Swenson and Wahr [22], and Landerer and Swenson [23]. The gridded data was scaled by the Land Scaling Grid (CLM4.SCALE_FACTOR.DS.G200KM) obtained from the same site, to restore energy removed by destriping, gaussian and degree 60 filters for each 1 degree bin. The dates used were from January 2003-February 2013, excluding the following months, where no solution is provided: June 2003, January 2011, June 2011, December 2011, May 2012, and October 2012, and using the monthly solution from 2 January 2012 in place of the December 2011 data. As none of the missing data were located during a peak or trough in the annual fluctuations, the remaining gaps in this time series were filled by linear interpolation between adjacent months' mass anomaly values. 
Using error calculation methods detailed in Landerer et al., [23], error estimates are calculated from a combination of measurement and leakage errors. Error measurements for $1 \times 1$ degree marshes $\sigma=7.85 \mathrm{~cm}$, for $3 \times 3$ degree marshes $\sigma=2.71 \mathrm{~cm}$, the middle watershed $3 \times 3$ degree $\sigma=6.03 \mathrm{~cm}$, and for the upper watershed $5 \times 5$ degree $\sigma=3.17 \mathrm{~cm}$.

A spatial average of mass directly over the marshes, as well as in the upper and middle watershed was calculated from $1 \times 1,3 \times 3$ and $5 \times 5$ degree boxes for each date in the time series. An annual sine function and linear trend is simultaneously fitted to the multi-year trends in the temporal data series, and tested for significant difference from zero slope $(\alpha=0.05)$ [24,25]. Error is calculated for each slope term through propagation of errors using the covariance matrix. To assess changes in marshland extent, MODIS 8 day, $500 \mathrm{~m}$, surface reflectance image composite scenes (MOD09A1) both before and covering the same time period as the GRACE data (2000-2013) were selected. Based on a review of an entire year (2003) of images to determine timing of maximum surface water extent in the Iraqi Marshes system, MODIS scenes for each year were selected to coincide with this maximum extent (second week in March). In 2006 and 2010, images from 1 to 2 weeks later were selected due to early March cloud cover obscuring areas of open water resulting in underestimation of marsh extent. These images were re-projected into an equal area projection to calculate areas.

Normalized difference vegetation index (NDVI) and modified normalized difference water index (MNDWI) images were calculated for the Iraqi Marshes region, (Figure 2). NDVI was used to determine marshland and irrigated land extent. NDVI is a measure of vegetation greenness [26], and in the marshes provides a simple measure of vegetation extent, especially as the area surrounding the marshes is either barren or desert land. The equation for NDVI is:

$$
(\mathrm{IR}-\mathrm{R}) /(\mathrm{IR}+\mathrm{R})
$$

The Modified Normalized Difference Water Index (MNDWI) is an index used to determine extent of open water and has been used to determine open water extent of wetlands successfully [27,28]. By using what $\mathrm{Xu}$ [27] calls the MIR band (such as Landsat Band 5, covering 1.55-1.75 microns FWHM), in place of the IR band used in the Normalized Difference Water Index (NDWI) (Landsat Band 4, covering $0.76-0.90$ microns), it is possible to achieve reliable quick discrimination of open water features [27]. This method works well due to the extremely high absorption of water throughout the infrared region, particularly relative to the visible region (represented by the green band). When tested against visual inspection of aerial photos in wetlands environments in the US Prairie Pothole region, this was found to provide an estimate of open water extent accurate to between $0.5 \%$ and $1.5 \%$ of the open water area derived from aerial photos [28]. MNDWI is defined as:

$$
(\mathrm{GR}-\mathrm{MIR}) /(\mathrm{MIR}+\mathrm{GR})
$$

MODIS bands 4 (0.545-0.565 microns), 1 (0.620-0.670 microns), 2 (0.841-0.876 microns) and 6 (1.63-1.65 microns) were used for Green (GR), Red (R), near infra-red (IR), mid infrared (MIR), respectively.

A uniform threshold was applied to MNDWI and NDVI images to identify the areal coverage of the wetlands. From these, areas of open water and vegetation were calculated in a GIS environment. 
Figure 2. Combined MODIS NDVI-MNDWI images for 2001-2012, over Iraqi Marshes. Open water is shown in blue (MNDWI $>0$ ), high vegetation is shown in green, medium in yellow, and low in brown.
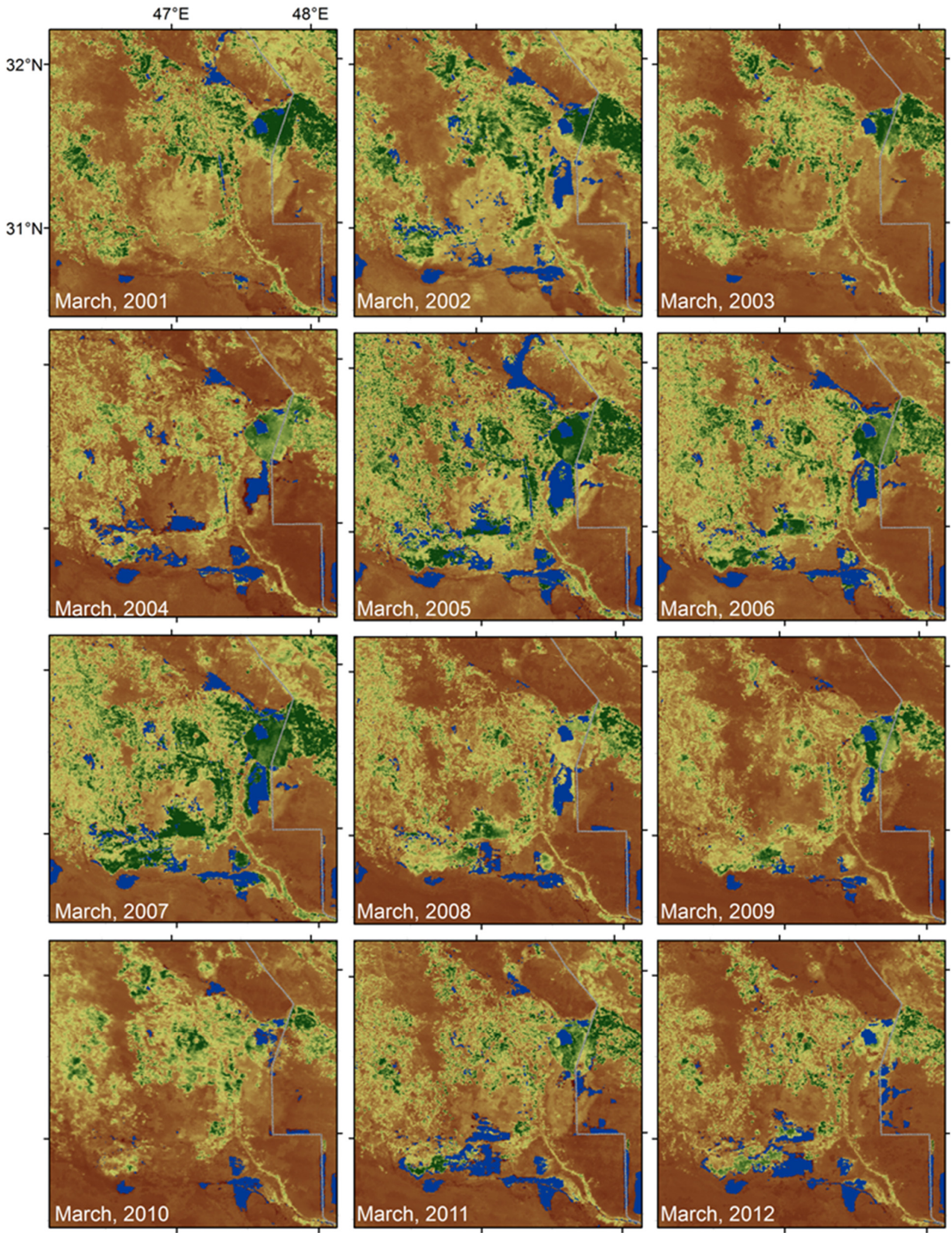

† $\frac{\text { Kilometers }}{02550 \quad 75 \quad 100}$ 
To assess precipitation in the same time period, the "TRMM and Other Data Precipitation Product (TRMM 3B43)" Version 7 TRMM Multi-Satellite Precipitation Analysis of monthly precipitation data were compiled for the period 1998-2013 [29]. This is a derived product dataset which includes measurements from TRMM, Special Sensor Microwave Imager (SSM/I), and rainfall gauges that are integrated into a 0.25 degree spaced average hourly precipitation rate as a monthly product. Monthly global precipitation data from January 1998 through October 2013 were stacked based on geo-location. Hourly rates were converted to total precipitation for each month, and annual precipitation was calculated both for each water year (August through the following July), and average annual precipitation rates for the entire period. Precipitation was reprojected to an Albers equal area projection, and spatially averaged for the entire watershed to allow comparison between individual years and the $15 \mathrm{yr}$ average.

\section{Results}

MODIS data was used to map the extent of changes in the Iraqi Marshes from 2000 to 2013. Figure 2 shows the extent of change in both open water and in vegetated area between 2001 and 2012. A low in both open water and vegetated area are seen in 2003, prior to the alterations from the Second Gulf War. In 2004-2006, open water is seen to increase, and along with it increased vegetated areas. This falls off between 2008 and 2009, reaching a low in open water in 2009, and vegetation in 2010. The area covered by open water together with vegetation expanded through 2011, and again in 2013.

The mapped extent of open water and healthy vegetated area is shown in Figure 3. Water equivalent depth changes derived from GRACE data with annual average signal removed for $1 \times 1$ degree area centered on the Marshlands are overlain on this figure and show the same patterns as are seen in the combined areal extent of open water and healthy vegetation in the MODIS data. Both the $1 \times 1$ and $3 \times 3$ areas over the marshes show the same pattern, with the water equivalent thickness of the $3 \times 3$ averaged data being lower, due to large areas of desert that it incorporates (Figure 4). From these it is seen that the GRACE data can be used to map trends in wetlands area in Iraqi Marshes.

Prior to 2003, the marshes extent was minimized by active drainage and water diversion. In 2003-2005 the Iraqi Marshes experienced a great increase both in areal extent and in mass, presumably from increased water storage. Recovery during this time period can be seen in Figure 2, and is also clearly seen in increased open water and increased vegetated area (Figure 3). For the period 2006-2009, there is a sharp decline in water in the Iraqi Marshes. This is reflected in change in areal extent seen in MODIS images (Figure 2), and in the decline both in open water extent and vegetated area, and in GRACE water equivalent thickness (Figure 3). For the period March 2009-March2012, the Iraqi Marshes experience both wetting and drying periods, with only one year having precipitation above average (August 2009-July 2010 water year) (Figure 5).

GRACE results from the lower portion of the T-E over the Iraqi Marshes were compared with results computed from the upper portion of the Tigris Euphrates basin (Figure 4, Table 1). Based on this comparison, several points are evident. 
Figure 3. MODIS derived area for open water (blue), high NDVI (green, surrogate for healthy marshland vegetation) in the area shown in Figure 2. Water equivalent depth changes derived from GRACE data with annual average signal removed for $1 \times 1$ degree area centered on the Marshlands is overlain in red showing agreement between GRACE solution and extent of combined open water and high NDVI regions. MODIS bars are centered over the GRACE acquisition for the same month.

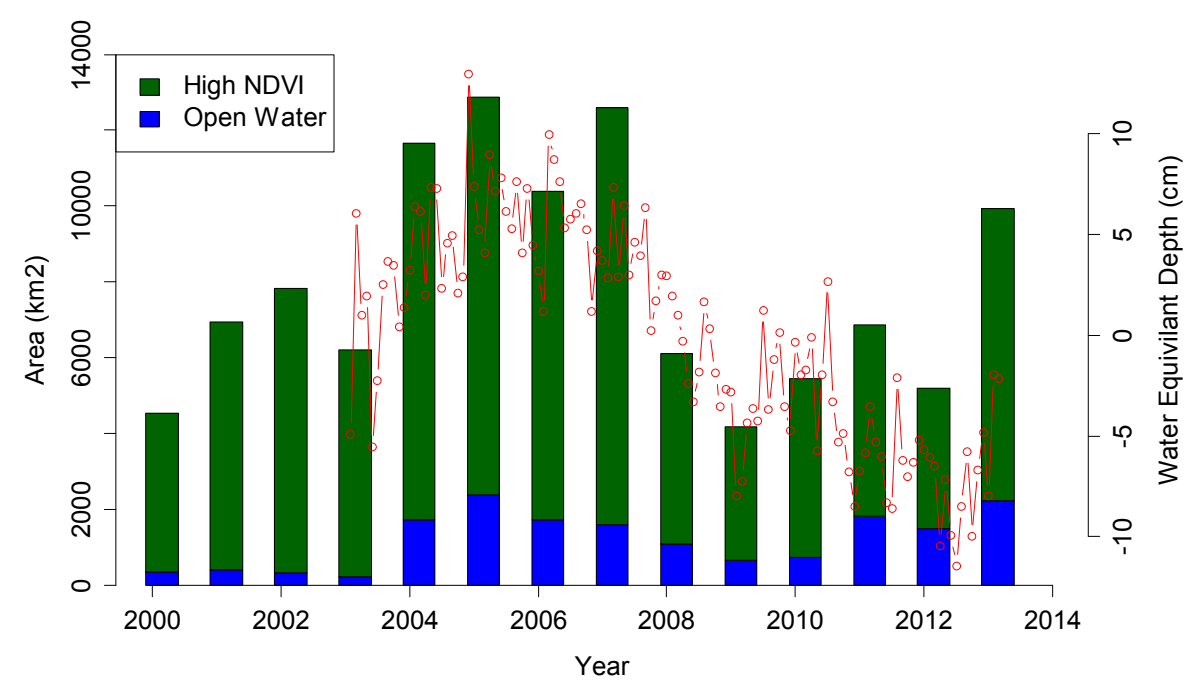

Figure 4. Water equivalent depth changes derived from GRACE data for $1 \times 1$ degree area centered on the Marshlands, a $3 \times 3$ area centered on the marshlands, a $3 \times 3$ area in the middle of the T-E watershed, and a $5 \times 5$ degree area in the upper TE watershed. Standard errors for each measurement are shown in gray. Overlain on these are statistically significant $(\alpha=0.05)$ best fit model of annual and trend component combined (blue) and linear trend alone (black). Dashed line indicates no trend significantly different from zero slope. Lines show trends in water storage for the time period January 2003-March 2013. Slope and error for each segment are listed in Table 1.
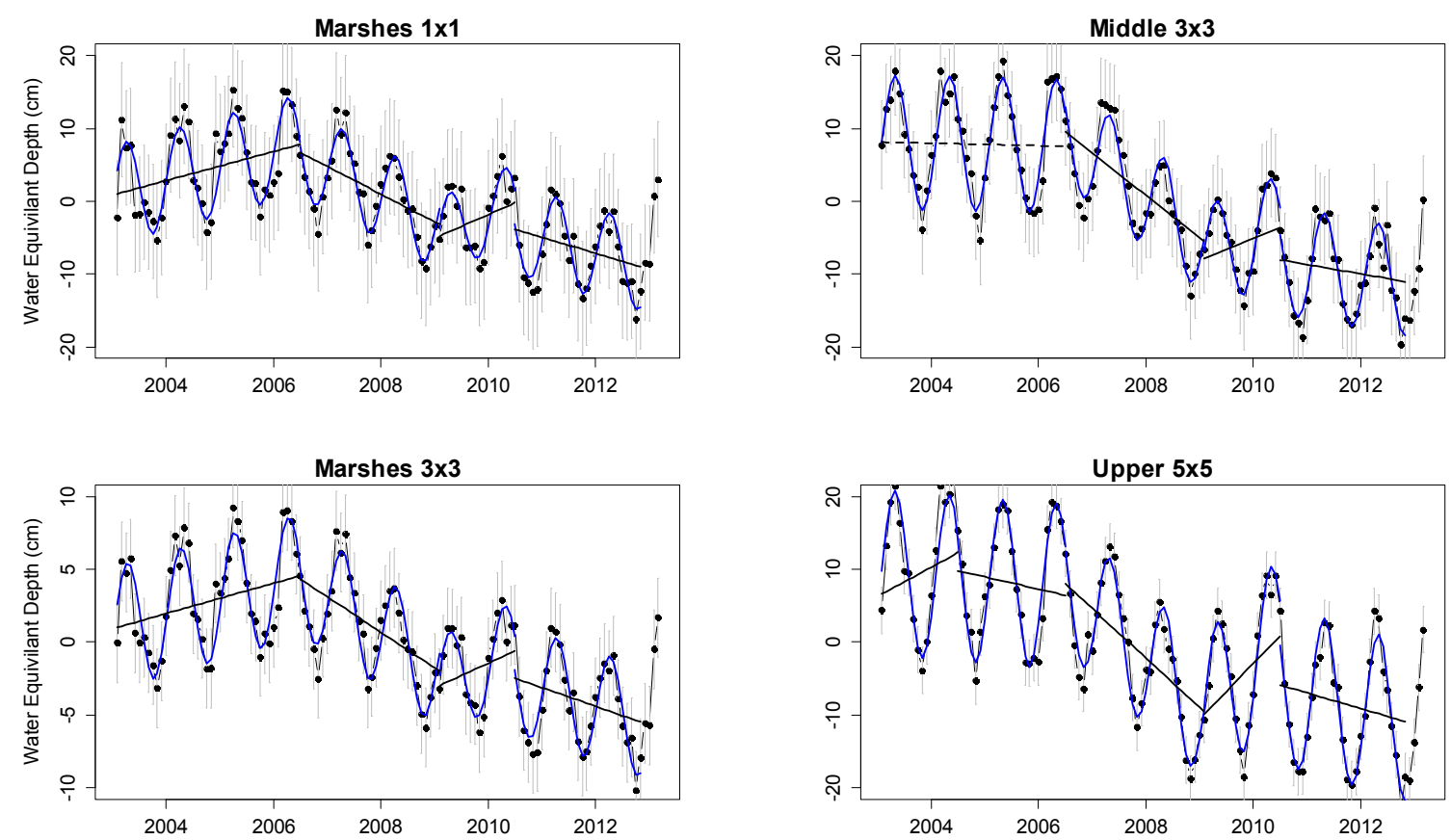
Table 1. Slopes of best fit linear trends and associated standard errors in $\mathrm{cm} / \mathrm{year}$ for time periods T1: January 2003-June 2006, T2: June 2006-January 2009, T3: January 2009-June 2010, T4: June 2010-October 2012. All are statistically significant $(\alpha=0.05$ ), except for T1 over the middle and upper areas, which do not show a slope statistically different from zero for that period (marked by * in the table). However, when broken into two linear segments, T1 shows a significant $(\alpha=0.05)$ positive, then negative trend (shown as "early" and "late").

\begin{tabular}{|c|c|c|c|c|c|c|c|c|}
\hline \multirow{2}{*}{ Location } & \multicolumn{8}{|c|}{ Time Period } \\
\hline & T1 & $\sigma_{\mathrm{T} 1}$ & $\mathbf{T 2}$ & $\sigma_{\mathrm{T} 2}$ & T3 & $\sigma_{\mathrm{T} 3}$ & T4 & $\sigma_{\mathrm{T} 1}$ \\
\hline Marshes $1 \times 1$ & 1.99 & 1.20 & -3.82 & 1.83 & 3.26 & 4.31 & -2.19 & 2.09 \\
\hline Marshes $3 \times 3$ & 1.04 & 0.41 & -2.44 & 0.63 & 1.72 & 1.49 & -1.29 & 0.72 \\
\hline Middle $3 \times 3$ & $*$ & $*$ & -5.80 & 1.41 & 2.99 & 3.31 & -1.28 & 1.61 \\
\hline Upper $5 \times 5$ & $*$ & $*$ & -6.79 & 0.74 & 7.52 & 1.74 & -2.15 & 0.85 \\
\hline Upper $5 \times 5$ early & 4.04 & 1.73 & & & & & & \\
\hline Upper $5 \times 5$ late & -1.68 & 1.13 & & & & & & \\
\hline
\end{tabular}

Figure 5. Average annual rainfall for the Tigris Euphrates watershed from TRMM 3B43 data product. Rainfall is calculated by local water year (August through July of the following year). Mean precipitation line shows average for TRMM (January 1998-October 2013) for the entire basin.

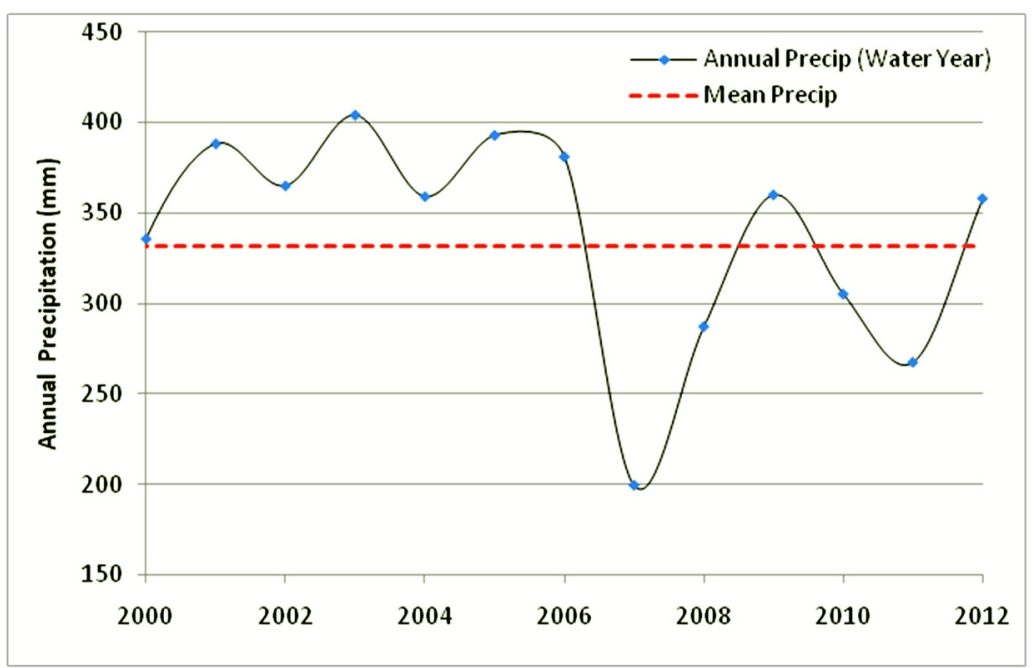

During the same time period that the marshes were showing an increase in water storage (2003-2006), water equivalent mass in the upstream area experiences first an increase, then a decrease, with a zero net change (Figure 4). In 2006-2009, the same sharp decrease is seen in upstream portions of the T-E watershed that is seen in the middle watershed and in the marshes. In the last portion of the record (2009-2012), the mass variations in the upper watershed are seen to be larger in magnitude, but the same direction and relative amount as those over the marshes.

Cross correlations of mass variations between the upper and lower portions of the T-E watershed were performed to assess relationships between upper and lower portions of the system. Across the entire time period, cross correlation of upper and marsh area mass variations prior to annual signal removal showed a maximum correlation $(R=0.89)$ when the marshes storage changes lag those in the 
upper portion of the watershed by one month. This suggests that mass is moving through the system on roughly a one month time scale. For the period T1, cross correlation between upper and marshes following annual signal removal was low at $\mathrm{R}=0.40$ with no lag. For the period following 2006 (T2-T4), cross correlation of upper watershed and marshes (both $3 \times 3$ and $1 \times 1$ ) was very good and showed a maximum correlation of $\mathrm{R}=0.88(3 \times 3)$ and $0.86(1 \times 1)$ at no lag. There were lower correlations between the middle $\mathrm{T}$-E and marshes (both $1 \times 1$ and $3 \times 3)$ during $\mathrm{T} 1(\mathrm{R}=0.30,0.18)$, but almost identical correlations in the period following $2006(\mathrm{R}=0.92,0.88)$.

Precipitation in the T-E from TRMM 3B43 data showed no significant trends in annual total precipitation (Figure 5). For the years 2000-2006, precipitation was above the average for the $15 \mathrm{yr}$ TRMM record. However during both 2007 and 2008 water years, the precipitation was substantially below the long term average, above average for 2010, and falling again in 2011 and 2012. The $2 \mathrm{yr}$ period of 2007-2008 is $25 \%$ below the $15 \mathrm{yr}$ average, and the $5 \mathrm{yr}$ period average from 2007 to 2011 is $15 \%$ below the longer term average. These patterns are consistent with the changes in mass shown in the GRACE data for the entire study period. When precipitation is above the mean, the GRACE mass data show either a positive or no trend. When precipitation is below average, GRACE data show a negative trend in mass. The one exception to this is that the negative mass trend in the marshes and middle watershed appears to begin in the middle of 2006, preceding the reduced precipitation seen in 2007-2008.

\section{Discussion}

GRACE mass variations expressed as water equivalent depth agree with MODIS derived marshland extents. Trends in GRACE data show different behavior between upper watershed and marshes in 2003-2006, and similar trends in all three areas in following time periods. A five year period where the average precipitation is $15 \%$ below the $15 \mathrm{yr}$ average which includes a two year period of precipitation averaging $25 \%$ below the $15 \mathrm{yr}$ average coincides with extreme drying in the marshes.

GRACE data best reflect variation not just in open water, but in entire marshland area with healthy vegetation. This is likely because the increased vegetation reflects a response to increased water in the marshlands. This is particularly evident in the time series from 2004 to 2006, where open water areas are established and then in-filled with emergent marshland vegetation.

The changes in water mass during the 2003-2013 time period reflect both differences in precipitation and differences in how the entire T-E system functioned during the time period. The GRACE datasets show a gradual decrease in total water in the source water regions for the Tigris and Euphrates over the period of 2003-2008, followed by fluctuations since 2009, indicating increased drying of the system, followed by cycles of rewetting and drying. However, in the area of the marshes, the mass change is the opposite for the years 2003-2006, with a sharp change in the lower portion of the watershed containing the Iraqi Marshes in 2006 from increasing to losing water surface area and mass. After 2006, the water mass in the marshes tracks the upstream patterns.

In the 2003-2006 period, the GRACE mass data show clearly that the marshes and upper watershed were functioning independently. There is above average rainfall during this time period, and precipitation is sufficient to provide water flow throughout the system, even considering the diversion 
and storage of upstream water. This water flow is sufficient to allow the recovery of the marshes to their largest extent following the destruction of local diversions and pumps.

In 2007-2008, precipitation dropped by an average of $25 \%$ below the mean annual total for the watershed, and the mass in the upper and lower watershed fell substantially. The water which had previously been sufficient both to support upstream diversions and marshland recovery was no longer sufficient for either. At this point, the marshes have become re-coupled to the flow through the T-E system, and are affected by the overall behavior of the system. Both the MODIS image from March of 2013 and GRACE results until February 2013 show that this period of drying coupled with this drought in the T-E system drought may have come to an end.

When precipitation in the T-E system drops below the $15 \mathrm{yr}$ average, the marshes enter a drying phase. A drop of $15 \%$ below the average, such as was observed between the 2007 and 2011 water years (ending in 2012), seems to be sufficient to cause drying with the current upstream diversions in place. Model results from the CMIP 3 ensemble of climate models suggest that this magnitude of precipitation reduction should be expected in the latter part of the century over the T-E watershed with smaller, reductions occurring in mid-century [30,31]. This suggests that though the recovery appeared to be well on its way in 2006 , but the reduced flow in the middle to latter portion of the century will make that recovery un-sustainable. As the future recovery is linked to upstream water availability, predicted precipitation and temperature trends indicate that the marshes may never recover to a sustainable size. Once precipitation regularly drops below the current mean, the current water allocation scenario will not allow the marshlands to recover, which will deplete the primary freshwater supply into the Gulf, and will eventually impair the water quality in the ecosystem which depends on it [32-34].

\section{Conclusions}

A combination of GRACE time series gravity anomaly data and MODIS derived wetlands extent were used to determine the extent of changes in the Iraqi Marshes from 2003 to 2013. GRACE derived water equivalent mass variations were found to correlate with total marshlands extents derived from MODIS (Figure 2). Marshland extents rebounded strongly from 2003 to 2006, shrank beginning in 2006, experiencing a low period from 2009 until 2012, and may have begun a recovery in 2013. Changes in marshland extent from 2003 to 2006 were poorly correlated with upstream water mass variations, suggesting that the marshland extent during this period was dominated by recovery from previous diversions and pumping that had been in place from the 1990s until just prior to the study period. Following 2006 until 2013, the gravity anomalies in the marshes as well as middle and upper portions of the Tigris-Euphrates watershed were highly correlated, suggesting that the marshes had achieved equilibrium with river inputs, and was responding to upstream water availability, and no longer dominated be recovery from previous diversions. The effects of extended drought, shown in the TRMM precipitation record to have reduced precipitation in the watershed by as much as $25 \%$ below mean annual precipitation levels over $2 \mathrm{yr}$, and by $\sim 15 \%$ over $5 \mathrm{yr}$ is shown to reduce the surface water area of the marshes seen by MODIS, and the water mass seen by GRACE to levels seen prior to recovery from direct anthropogenic manipulation of the wetlands system. Based on ensemble climate predictions for the region, and the marshes response the observed drought conditions between 2007 
and 2011, predicted precipitation and temperature trends indicate that the marshes may not ultimately recover to a size larger than the 4,000-6,000 $\mathrm{km}^{2}$ that was seen from 2007 to 2011.

\section{Acknowledgments}

GRACE land data were processed by Sean Swenson, supported by the NASA MEaSUREs Program, and available at http://grace.jpl.nasa.gov. Thanks to K. Winfield for dataset preparation and D. Becker for review and editing of this manuscript. Thanks to three anonymous reviewers whose input improved this paper.

\section{Conflicts of Interest}

The author declares no conflict of interest.

\section{References}

1. Beaumont, P. Restructuring of Water Usage in the Tigris-Euphrates Basin: The Impact of Modern Water Management Projects. In Transformation of Middle Eastern Natural, Environments: Legacies and Lessons; Coppock, J., Miller, J.A., Eds.; Yale University: New Haven, CT, USA, 1998; pp. 168-186.

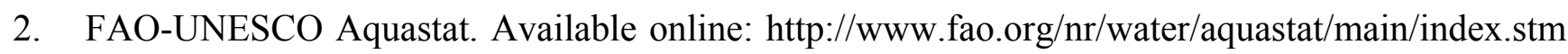
(accessed on 21 July 2013).

3. Jones, C.; Sultan, M.; Yan, E.; Milewski, A.; Hussein, M.; Al-Dousari, A.; Al-Kaisy, S.; Becker, R. Hydrologic impacts of engineering projects on the Tigris-Euphrates system and its marshlands. J. Hydrol. 2008, 353, 59-75.

4. Al-Ansari, N.; Knutsson, S.; Ali, A.A. Restoring the Garden of Eden, Iraq. J. Earth Sci. Geotech. Eng. 2012, 2, 53-88.

5. United Nations Environmental Programme. The Mesopotamian Marshlands: Demise of an Ecosystem, Early Warning and Assessment Report; UNEP/DEWA/TR.01-3 Rev.1; Division of Early Warning and Assessment, United Nations Environmental Programme: Nairobi, Kenya, 2001.

6. Salman, M. The Euphrates and Tigris: South Boundary Utilization and Views. In Water, Development and Cooperation-Comparative Perspective: Euphrates-Tigris and Southern Africa, Paper 46; Wirkus, L., Ed., Bonn International Center for Conversion, Bonn, Germany, 2005; pp. 136-156.

7. Bayazit, M.; Avci, I. Water resources of Turkey: Potential, planning, development and management. Int. J. Water Resour. Dev. 1997, 13, 443-452.

8. Yuksel, I. Water development for hydroelectric in southeastern Anatolia project (GAP) in Turkey. Renew. Energy 2012, 39, 17-23.

9. Akpinar, A.; Kaygusuz, K. Regional sustainable water and energy development projects: A case of Southeastern Anatolia Project (GAP) in Turkey. Renew. Sustain. Energy Rev. 2012, 16, 1146-1156.

10. Scott, D.A. A Directory of Wetlands in the Middle East; IUCN-The World Conservation Union and International Waterfowl and Wetlands Research Bureau: Gland, Switzerland and Slimbridge, UK, 1995. 
11. Voss, K.A.; Famiglietti, J.S.; Lo, M.; de Linage, C.; Rodell, M.; Swenson, S.C. Groundwater depletion in the Middle East from GRACE with implications for transboundary water management in the Tigris-Euphrates-Western Iran region. Water Resour. Res. 2013, 49, 904-914.

12. Longuevergne, L.; Wilson, C.R.; Scanlon, B.R.; Crétaux, J.F. GRACE water storage estimates for the Middle East and other regions with significant reservoir and lake storage. Hydrol. Earth Syst. Sci. Discuss. 2012, 9, 11131-11159.

13. Rodell, M.; Houser, P.R.; Jambor, U.; Gottschalck, J.; Mitchell, K.; Meng, C.J.; Arsenault, K.; Cosgrove, B.; Radakovich, J.; Bosilovich, M.; et al. The global land data assimilation system. Bull. Am. Meteorol. Soc. 2004, 85, 381-394.

14. Li, B.; Rodell, M.; Zaitchik, B.F.; Reichle, R.H.; Koster, R.D.; van Dam, T.M. Assimilation of GRACE terrestrial water storage into a land surface model: Evaluation and potential value for drought monitoring in western and central Europe. J. Hydrol. 2012, 446-447, 103-115.

15. Tapley, B.D.; Bettadpur, S.; Ries, J.C.; Thompson, P.F.; Watkins, M.M. GRACE measurements of mass variability in the Earth system. Science 2004, 305, 503-505.

16. Rodell, M.; Famiglietti, J.S. Detectability of variations in continental water storage from satellite observations of the time dependent gravity field. Water Resour. Res. 1999, 35, 2705-2723.

17. Tiwari, V.M.; Wahr, J.; Swenson, S. Dwindling groundwater resources in northern India, from satellite gravity observations. Geophys. Res. Lett. 2009, 36, doi:10.1029/2009GL039401.

18. Cheng, M.K.; Tapley, B.D. Variations in the Earth's oblateness during the past 28 years. J. Geophys. Res.: Solid Earth 2004, 109, doi:10.1029/2004JB003028.

19. Swenson, S.; Chambers, D.; Wahr, J. Estimating geocenter variations from a combination of GRACE and ocean model output. J. Geophys. Res. Solid Earth 2008, 113, doi:10.1029/2007JB005338.

20. Paulson, A.; Zhong, S.; Wahr, J. Modelling post-glacial rebound with lateral viscosity variations. Geophys. J. Int. 2005, 163, 357-371.

21. Geruo, A.; Wahr, J.; Zhong, S. Computations of the viscoelastic response of a 3-D compressible Earth to surface loading: An application to Glacial Isostatic Adjustment in Antarctica and Canada. Geophys. J. Int. 2013, 192, 557-572.

22. Swenson, S.; Wahr, J. Estimating large-scale precipitation minus evapotranspiration from GRACE satellite gravity measurements. J. Hydrometeorol. 2006, 7, 252-270.

23. Landerer, F.W.; Swenson, S.C. Accuracy of scaled GRACE terrestrial water storage estimates. Water Resour. Res. 2012, 48, doi:10.1029/2011WR011453.

24. Velicogna, I.; Wahr, J. Measurements of time-variable gravity show mass loss in Antarctica. Science 2006, 311, 1754-1756.

25. Chen, J.L.; Wilson, C.R.; Blankenship, D.D.; Tapley, B.D. Antarctic mass rates from GRACE. Geophys. Res. Lett. 2006, 33, L11502.

26. Rouse, J.W.; Haas, R.H.; Schell, J.A.; Deering, D.W. Monitoring Vegetation Systems in the Great Plains with ERTS. In Third Earth Resources Technology Satellite-1 Symposium-Volume I: Technical Presentations; NASA SP-351; NASA: Washington, DC, USA, 1974; pp. 309-317.

27. $\mathrm{Xu}, \mathrm{H}$. Modification of normalised difference water index (NDWI) to enhance open water features in remotely sensed imagery. Int. J. Remote Sens. 2006, 27, 3025-3033.

28. Ouyang, Z.; Becker, R.; Shaver, W.; Chen, J. Evaluating the sensitivity of wetlands to climate change with remote sensing techniques. Hydrol. Process. 2014, 28, 1703-1712. 
29. Huffman, G.J.; Adler, R.F.; Bolvin, D.T.; Nelkin, E.J. The TRMM Multi-Satellite Precipitation Analysis (TMPA). In Satellite Rainfall Applications for Surface Hydrology; Hossain, F., Gebremichael, M., Eds.; Springer: Dordrecht, The Netherlands/Heidelberg, Germany/London, UK/New York, NY, USA, 2010.

30. Bozkurt, D.; Sen, O.L. Climate change impacts in the Euphrates-Tigris Basin based on different model and scenario simulations. J. Hydrol. 2013, 480, 149-161.

31. Chenoweth, J.; Hadjinicolaou, P.; Bruggeman, A.; Lelieveld, J.; Levin, Z.; Lange, M.A.; Xoplaki, E.; Hadjikakou, M. Impact of climate change on the water resources of the eastern Mediterranean and Middle East region: Modeled 21st century changes and implications. Water Resour. Res. 2011, 47, doi:10.1029/2010WR010269.

32. Al-Yamani, F. Importance of the Freshwater Influx from the Shatt-Al-Arab River on the Gulf Marine Environment. In Protecting the Gulf's Marine Ecosystems from Pollution; Abuzinada, A.H., Barth, H.J., Krupp, F., Boer, B., AlAbdessalaam, T.Z., Eds.; Birkhäuser Basel: Basel, Switzerland, 2008; pp. 207-222.

33. Al-Yamani, F.Y.; Bishop, J.M.; Al-Rifaie, K.; Ismail, W. The effects of the river diversion, Mesopotamian Marsh drainage and restoration, and river damming on the marine environment of the northwestern Arabian Gulf. Aquat. Ecosyst. Health Manag. 2007, 10, 277-289.

34. Sheppard, C.; Al-Husiani, M.; Al-Jamali, F.; Al-Yamani, F.; Baldwin, R.; Bishop, J.; Benzoni, F.; Dutrieux, E.; Dulvy, N.K.; Durvasula, S.R.V.; et al. The Gulf: A young sea in decline. Mar. Pollut. Bull. 2010, 60, 13-38.

(C) 2014 by the authors; licensee MDPI, Basel, Switzerland. This article is an open access article distributed under the terms and conditions of the Creative Commons Attribution license (http://creativecommons.org/licenses/by/3.0/). 